\title{
Deduction of duodenal ulcer recurrence by healing with cimetidine plus sulpiride
}

\author{
M TATSUTA, H IISHI, AND S OKUDA \\ From the Department of Gastrointestinal Oncology, and Department of Gastroenterology, The Center for \\ Adult Diseases, Osaka, Japan
}

SUMmaRY The effect of combined treatment with sulpiride plus cimetidine was compared against that of cimetidine alone on the healing of duodenal ulcer and on the subsequent relapse rate. In a double blind study, 35 patients with duodenal ulcer diagnosed by endoscopy were randomly assigned to receive cimetidine $800 \mathrm{mg}$ daily and 38 patients to receive cimetidine 800$) \mathrm{mg}$ plus sulpiride $200 \mathrm{mg}$ daily. Sixty patients whose ulcers were healed at three months continued to be observed after stopping treatment and underwent endoscopy to detect recurrences when symptomatic or at three and at six months if asymptomatic. Recurrence was observed in $18(72 \%)$ of 25 patients whose ulcers had healed on cimetidine alone, but in only $11(38 \%)$ of 29 patients whose ulcers healed on cimetidine plus sulpiride.

Cimetidine, a histamine $\mathrm{H}_{2}$-receptor antagonist, heals the majority of duodenal ulcers within four to six weeks, ${ }^{1-3}$ but most of these ulcers quickly recur when treatment is discontinued. ${ }^{+9}$ The exact mechanism of early recurrence is unclear. Guslandi et $a l^{1011}$ and Arakawa and Kobayashi ${ }^{12}$ recently reported that cimetidine treatment results in an inadequacy of the mucosal defensive mechanism. Thus it would seem possible that the concomitant use of cimetidine and drugs that enhance mucosal defensive factors might prevent ulcer recurrence after withdrawal of treatment. Sulpiride, a nonsedative, hypothalamic neuroleptic, increases both mucosal blood flow in the gastroduodenal mucosa ${ }^{1.3}$ and mucus secretion. ${ }^{14}$ This drug has not been shown to be a potent acid lowering agent, although it reduces meal related serum gastrin. 15 Lam et $a l^{16}$ and Mihas and Mihas ${ }^{17}$ reported a high ulcer healing rate with an antacid sulpiride combination, and suggested that sulpiride might be a helpful adjunct in ulcer treatment. In the present study, we therefore examined the effect of the combined use of sulpiride plus cimetidine on the recurrence of duodenal ulcer.

\section{Methods}

PATIENTS

Seventy three patients with endoscopically verified

Address for correspondence: Masaharu Tatsuta. MD. Department of Gastrointestinal Oncology. The Center for Adult Diseases. Osaka, 3-3. Nakamichi 1-chome. Higashinari-ku. Osaka 537. Japan.

Received for publication 10 March 1986 duodenal ulcers entered this double blind controlled trial. Informed consent was obtained from each subject, and the study was carried out in accordance with the Declaration of Helsinki. Endoscopic examinations were carried out less than seven days before starting treatment. All endoscopies were done by the same experienced endoscopist using a forward viewing fibreoptic panendoscope (Olympus GF- $\mathrm{P}_{3}$ ). The diameters of the ulcers were measured using the tip of the biopsy forceps. All patients were treated on an outpatient basis. By random allocation 35 patients were assigned to receive treatment with cimetidine only $(200 \mathrm{mg}$ three times daily after meals and at bedtime) and 38 patients to cimetidine plus sulpiride $(200 \mathrm{mg}$ of cimetidine and $50 \mathrm{mg}$ of sulpiride three times daily after meals and at bedtime). All patients kept a daily record of their consumption of drugs, and attended the hospital once every two weeks. Endoscopy was carried out three months after starting treatment by the same endoscopist, who had no knowledge of the patient's treatment or clinical progress. Healing was defined as a bulb free of an ulcer crater. Patients whose ulcers were not healed at three months were withdrawn from the study. The remaining patients had no further medication, but attended the hospital once every four weeks to check for symptom recurrence. Endoscopy was carried out at the time of symptom recurrence, or at three and six months in those who remained asymptomatic, once again by the same endoscopist who remained unaware of the patient's earlier treatment. The reappearance of an 
ulcer crater was considered a recurrence whether symptoms were present or not, but the reappearance of erosions alone was not considered a recurrence.

After being accepted into the study, the patients were interviewed in detail with particular reference to the duration of their illness, cigarette and alcohol consumption, and ingestion of aspirin or nonsteroidal, non-salicylate, anti-inflammatory drugs (NSNSAID).

The smoking index was defined as the number of cigarettes smoked per day multiplied by the duration of smoking in years. ${ }^{18}$ In calculating the duration of smoking, any continuous pause in smoking lasting more than one year was subtracted. Individuals with a smoking index of over 400 were defined as 'heavy smokers'. Non-smokers were defined as never having smoked. No patients who smoked a pipe and/or cigars only or in addition to cigarettes were included in this study.

Consumption of alcohol, aspirin, and NSNSAID was defined as follows: ${ }^{19}$

\section{ALCOHOL}

(1) Nil - less than $10 \mathrm{~g} /$ month; (2) Mild - 10 $\mathrm{g} / \mathrm{month}$ to less than $60 \mathrm{~g} /$ week; (3) Moderate $60 \mathrm{~g} /$ week to less than $60 \mathrm{~g} / \mathrm{day}$; (4) Heavy - $60 \mathrm{~g}$ or more/day for at least one month.

ASPIRIN AND NSNSAID

(1) Nil - less than one tablet or capsule per month;

(2) Mild - one to six tablets or capsules per month;

(3) Moderate - two or five tablets or capsules per week; (4) Heavy - six or more tablets or capsules per week for at least two consecutive months.

STATISTICAL ANALYSIS

This was done using the $\chi^{2}$ test. ${ }^{20}$ 'Significant' indicates a calculated $p$ value of $<0 \cdot 05$.

\section{Results}

HEALING OF ULCER

Ulcer healing at three months was similar in both treatment groups: in 28 of $35(80.0 \%)$ patients on cimetidine alone compared with 32 of $38(84 \cdot 2 \%)$ patients on cimetidine plus sulpiride. Thirteen patients (seven on cimetidine and six on combined treatment) were withdrawn as their ulcers had not healed.

Heavy smoking retarded healing. Thus healing occurred in all 13 non-smokers, in 16 of $19(84 \cdot 2 \%)$ patients with a smoking index of $1-400$, and in 31 of $41(75 \cdot 6 \%)$ of patients with a smoking index of over $400(\mathrm{p}<0 \cdot 02)$.

\section{ULCER RECURRENCE}

Sixty patients with healed duodenal ulcer entered the follow up phase of the trial. Six patients were withdrawn, five (two healed on cimetidine and three on combination treatment) because they refused endoscopy and the sixth (healed on cimetidine) because there was no follow up information.

The results are summarised in Table 1. At six months, of 25 patients treated with cimetidine only, ulcers reappeared in $18(72 \cdot 0 \%)$. In contrast, ulcers recurred in only 11 of $29(37.9 \%)$ patients who had been on combined cimetidine plus sulpiride $(p<0.05)$. Symptomatic recurrence was more frequent in the former group (in 10 of 25 patients, $40 \%$ ) than in the latter (five of $29,17 \cdot 2 \%$ ) but not significantly so. The reappearance of duodenal erosions alone in the bulb was observed in five $(20.0 \%)$ patients treated with only cimetidine but in none of those treated with cimetidine plus sulpiride.

Table 2 shows that the patients in the two groups did not differ significantly with respect to sex distribution, age, duration of illness, size of original ulcer, proportion of cigarette smokers and alcohol consumers, and proportion of habitual aspirin or NSNAID users.

FACTORS INFLUENCING ULCER RECURRENCE Ulcers recurred in 29 patients at or within six months, whereas 25 patients continued in remission off treatment. Recurrence was significantly more frequent in heavy smokers. Thus, of the patients

Table 1 Recurrence of duodenal ulcer six months after termination of treatment with cimetidine or cimetidine plus sulpiride

\begin{tabular}{|c|c|c|c|c|}
\hline \multirow[b]{2}{*}{ Treatment } & \multirow{2}{*}{$\begin{array}{l}\text { Patients } \\
\text { (n) }\end{array}$} & \multicolumn{3}{|c|}{ Recurrence (\%) } \\
\hline & & Total & Asymptomatic & Symptomatic \\
\hline Cimetidine & 25 & $18(72 \cdot 0)$ & 8 & 10 \\
\hline Cimetidine + sulpiride & 29 & $11(37.9)^{*}$ & 6 & 5 \\
\hline
\end{tabular}

*The difference between the incidences of ulcer recurrence after treatment with cimetidine only, and with cimetidine plus sulpiride was significant $(p<0 \cdot 05)$. 
Table 2 Clinical data of the patients with duodenal ulcer treated with cimetidine or cimetidine plus sulpiride

\begin{tabular}{lcc}
\hline Data & Cimetidine & $\begin{array}{l}\text { Cimetidine plus } \\
\text { sulpiride }\end{array}$ \\
\hline (n) & 25 & 29 \\
Men:women & $20: 5$ & $21: 8$ \\
Age (yr) & $48 \cdot 4 \pm 2 \cdot 2$ & $44 \cdot 5 \pm 2 \cdot 1$ \\
Duration of ulcer (yr) & $1 \cdot 3 \pm 0 \cdot 4$ & $1 \cdot 6 \pm 0 \cdot 4$ \\
Size of original ulcer (mm) & & \\
<-5 & $5(20 \cdot 0)$ & $7(24 \cdot 1)$ \\
5-10 & $12(48 \cdot 0)$ & $15(51 \cdot 8)$ \\
10 or more & $8(32 \cdot 0)$ & $7(24 \cdot 1)$ \\
Smoking index & & \\
$\quad 0$ & $6(24 \cdot 0)$ & $4(13 \cdot 8)$ \\
$\quad 1-400$ & $5(20 \cdot 0)$ & $8(27 \cdot 6)$ \\
400 or more & $14(56 \cdot 0)$ & $17(58 \cdot 6)$ \\
Alcohol & & \\
None & $12(48 \cdot 0)$ & $19(65 \cdot 5)$ \\
Mild & $6(24 \cdot 0)$ & $7(24 \cdot 2)$ \\
Moderate & $5(20 \cdot 0)$ & $1(3 \cdot 4)$ \\
Heavy & $2(8 \cdot 0)$ & $2(6 \cdot 9)$ \\
Aspirin & & \\
None & $22(88 \cdot 0)$ & $25(86 \cdot 2)$ \\
Mild & $3(12 \cdot 0)$ & $3(10 \cdot 4)$ \\
Moderate & $0(0 \cdot 0)$ & $0(0 \cdot 0)$ \\
Heavy & $0(0 \cdot 0)$ & $0(0 \cdot 0)$ \\
NSNSAID & & \\
None & $22(88 \cdot 0)$ & $23(79 \cdot 3)$ \\
Mild & $2(8 \cdot 0)$ & $5(17 \cdot 3)$ \\
Moderate & $1(4 \cdot 0)$ & $1(3 \cdot 4)$ \\
Heavy & $0(0 \cdot 0)$ & $0(0 \cdot 0)$ \\
\hline None & & \\
\hline
\end{tabular}

None of the differences between groups was statistically significant. Values indicate means $\pm S E$, and numbers in parentheses indicate percentage of cases.

with a smoking index of over 400 , ulcers recurred in 21 of 29 patients $(72 \cdot 4 \%)$ compared with in only 10 of 25 patients $(40 \%)$ who remained ulcer free $(p<0.05)$. Sex, age at presentation, duration of illness, size of the original ulcer, cigarette and alcohol consumption, and aspirin or NSNAID ingestion, however, did not show any significant correlation with ulcer recurrence.

\section{Discussion}

The possibility that $\mathrm{H}_{2}$-receptor antagonists might enhance the tendency of ulcers to relapse has been considered by numerous investigators, ${ }^{5-9}$ whereas after healing with drugs that act by other mechanisms such as colloidal bismuth ${ }^{21}$ or sucralfate ${ }^{22}$ it is rather lower. Although the exact mechanism of possible enhancement of ulcer recurrence after termination of cimetidine treatment is unclear, cimetidine does seem to impair the mucosal defensive mechanism. ${ }^{10-12} \mathrm{H}_{2}$-receptor antagonists and the mucosal-protective agents have been shown to
Table 3 Factors that may influence recurrence

\begin{tabular}{|c|c|c|}
\hline Factors & $\begin{array}{l}\text { Recurrent } \\
\text { ulcers }\end{array}$ & $\begin{array}{l}\text { Non-recurrent } \\
\text { ulcers }\end{array}$ \\
\hline (n) & 29 & 25 \\
\hline Men:women & $25: 4$ & $16: 9$ \\
\hline Age $(y r)$ & $47 \cdot 9 \pm 2 \cdot 1$ & $44 \cdot 5 \pm 2 \cdot 4$ \\
\hline Duratioin of ulcer $(\mathrm{yr})$ & $1 \cdot 6 \pm 0 \cdot 4$ & $1 \cdot 3 \pm 0 \cdot 3$ \\
\hline \multicolumn{3}{|c|}{ Size of original ulcer $(\mathrm{mm})$} \\
\hline$<-5$ & $7(24 \cdot 1)$ & $5(20 \cdot 0)$ \\
\hline $5-10$ & $14(48 \cdot 3)$ & $13(52 \cdot 0)$ \\
\hline 10 or more & $8(27 \cdot 6)$ & $7(28 \cdot 0)$ \\
\hline \multicolumn{3}{|l|}{ Smoking index } \\
\hline 0 & $3(10 \cdot 4)$ & $7(28 \cdot 0)$ \\
\hline $1-400$ & $5(17 \cdot 2)$ & $8(32 \cdot 0)$ \\
\hline 400 or more & $21(72 \cdot 4)$ & $10(40 \cdot 0)$ \\
\hline \multicolumn{3}{|l|}{ Alcohol } \\
\hline None & $15(51 \cdot 7)$ & $16(64 \cdot 0)$ \\
\hline Mild & $7(24 \cdot 2)$ & $6(24.0)$ \\
\hline Moderate & $4(13 \cdot 8)$ & $2(8 \cdot 0)$ \\
\hline Heavy & $3(10 \cdot 3)$ & $1(4 \cdot 0)$ \\
\hline \multicolumn{3}{|l|}{ Aspirin } \\
\hline None & $24(82 \cdot 8)$ & $23(92 \cdot 0)$ \\
\hline Mild & $4(13 \cdot 8)$ & $2(8 \cdot 0)$ \\
\hline Moderate & $0(0.0)$ & $0(0 \cdot 0)$ \\
\hline Heavy & $1(3 \cdot 4)$ & $0(0 \cdot 0)$ \\
\hline \multicolumn{3}{|l|}{ NSNSAID } \\
\hline None & $24(82 \cdot 8)$ & $21(84 \cdot 0)$ \\
\hline Mild & $4(13 \cdot 8)$ & $3(12 \cdot 0)$ \\
\hline Moderate & $1(3 \cdot 4)$ & $1(4 \cdot 0)$ \\
\hline Heavy & $0(0 \cdot 0)$ & $0(0 \cdot 0)$ \\
\hline
\end{tabular}

The differences of the incidence of heavy smokers with a smoking index of more than $4(0)$ between the patients in whom ulcer did or did not recur was statistically significant $(p<0 \cdot 05)$. Values indicate means $\pm S E$, and numbers in parentheses are percentage of cases.

prevent ulcer formation by a large variety of ulcer inducing techniques in animals. ${ }^{23}$

The known gastrointestinal effects of sulpiride include improvement of blood flow to the gastroduodenal mucosa ${ }^{13}$ and enhancement of mucus secretion. ${ }^{14}$ The drug does not affect the basal or histamine stimulated acid output after chronic treatment. ${ }^{15}$ Lam et al ${ }^{16}$ and Mihas and Mihas ${ }^{17}$ reported that an antacid sulpiride regimen is very effective in ulcer healing. Lam et al ${ }^{16}$ suggested that by using a combination of antacid and sulpiride. it would be theoretically possible to control the cephalic and gastric phases of acid secretion which occur with meals. Sulpiride, however, has not been shown to have a potent acid lowering effect. ${ }^{15}$ Therefore, it seems likely that its effect on ulcer healing might be because of an improvement of mucosal defensive factors.

In the present study, we found that the combined use of cimetidine and sulpiride reduced recurrence of duodenal ulcers during the six month period after termination of cimetidine treatment, and therefore 
the protective effect of sulpiride exists even though the drug was given with cimetidine.

The causes of ulcer relapse have not been established. In the present work, we examined the influence of patient's variables on relapse rate. We found that heavy smoking was closely related to the ulcer recurrence, but no significant correlation between ulcer recurrence and other variables was found. These findings strongly indicate that physicians should encourage their patients to stop smoking, or failing this, reduce their daily cigarette consumption as much as possible. ${ }^{24}$

\section{References}

1 Ippoliti AF, Sturdevant RAL, Isenburg JI et al. Cimetidine versus intensive antacid therapy for duodenal ulcer. Gastroenterology 1978; 74: 393-5.

2 Korman MG, Shaw RG, Hansky J, Schmidt GT, Stern AI. Influence of smoking on healing rate of duodenal ulcer in response to cimetidine or high dose antacid. Gastroenterology 1981; 80: 1451-3.

3 Fedeli G, Auti M, Rapaccini GL, De Vitris I, Butti A, Civello IM. A controlled study comparing cimetidine treatment to an intensive anatacid regimen in the therapy of uncomplicated duodenal ulcer. Dig Dis Sci 1979; 24: 758-62.

4 Gudmand-Høyer E, Birger Jensen K, Krag E et al. Prophylactic effect of cimetidine in duodenal ulcer disease. Br Med J 1978; i: 1095-7.

5 Bodemar G, Walan A. Maintenance treatment of recurrent peptic ulcer by cimetidine. Lancet 1978; i: 403-7.

6 Martin DF, Hollanders D, May SJ et al. Difference in relapse rates of duodenal ulcer after healing with cimetidine or tripotassium dicitrato bismuthate. Lancet 1981; i: 7-10.

7 Wallace WA, Ott CME, Bearn AR. Perforation of chronic peptic ulcers after cimetidine. Br Med J 1977; ii: $865-6$.

8 Gray GR, McKenzie I, Smith IS, Crean GP, Gillespie G. Oral cimetidine in severe duodenal ulceration. Lancet 1977; i: 4-7.

9 Bivins BA, Rogers EL, Rapp RP et al. Clinical failure with cimetidine. Surgery 1980; 88: 417-27.

10 Guslandi M, Cambielli M, Bierti L, Tittobello A. Relapse of duodenal ulceration after cimetidine treatment. $B r$ Med J 1978; i: 718 .
11 Guslandi M, Testoni PA, Fesce E, Ballarin E, Tittobello A. Behaviour of gastric mucin during pirenzepine treatment. A double-blind controlled study versus cimetidine. Curr Ther Res 1980; 27: 714-8.

12 Arakawa T, Kobayashi K. Role of endogenous prostaglandines on ulcer relapse after cessation of cimetidine treatment. Jpn J Gastroenterol 1983; 80: 1818.

13 Zeniba T, Fujii K, Fujii Y, Ohya S. Effect of dogmathyl (sulpiride) on gastric movement and gastrin mucosal blood flow. Proc 5th Congress New Drug Treatment. Osaka: Fujisawa Pharmaceutical Co, 1968: 48-59.

14 Wada T. Peptic ulcer and gastric mucus secretion. Proc 6th Congress New Drug Treatment. Osaka: Fujisawa Pharmaceutical Co, 1969: 88-95.

15 Caldara R, Romussi M. Ferrari C. Inhibition of gastrin secretion by sulpiride treatment in duodenal ulcer patients. Gastroenterology 1978; 74: 221-3.

16 Lam SK, Lam KC, Lai CL et al. Treatment of duodenal ulcer with antacid and sulpiride. Gastroenterology 1979; 76: 315-22.

17 Mihas AA, Mihas TA. A controlled trial of an antacid-sulpiride regimen and cimetidine in the treatment of benign gastric ulcer. Gastroenterology 1981; 80: 1232 .

18 Staszewski J. Smoking and cancer of the alimentary tract in Poland. Br J Cancer 1969; 22: 247-53.

19 Piper DW, McIntosh JH, Greig M, Shy CM. Environmental factors and chronic gastric ulcer. A case control study of the association of smoking, alcohol, and heavy analgesic ingestion with the exacerbation of chronic gastric ulcer. Scand J Gastroenterol 1982; 17: 721-9.

20 Snedecor GW, Cochran WG. Statistical methods. Ames, Iowa: Iowa State University Press, 1967.

21 Martin DF, Hollander D, May SJ et al. Difference in relapse rates of duodenal ulcer after healing with cimetidine or tripotassium dicitrato bismuthate. Lancet 1981; i: 7-10.

22 Marks IN, Licke W, Wright JP, Girdwood AH. Ulcer healing and relapse rates after initial treatment with cimetidine or sucralfate. J Clin Gastroenterol 1981; 3: suppl 2: 163-5.

23 Bank S, Zimmerman H, Smolow C, Kranz V. Prevention of duodenal ulcers in the rat using a combination of ranitidine and sucralfate in subtherapeutic doses. Gut 1985; 26: 603-6.

24 Korman MG, Hansky J, Eaves R, Schmidt GT. Influence of cigarette smoking on healing and relapse in duodenal ulcer disease. Gastroenterology 1983; 85: $871-4$. 